\title{
Vaccination and Herd Immunity: Individual, Collective, and Institutional Responsibilities
}

\begin{abstract}
This chapter discusses the relation between collective, individual, and institutional responsibilities with regard to the realization of herd immunity from certain infectious diseases. The argument is put forth that there is a form of collective moral obligation to realize herd immunity, that there is a principle of fairness in the distribution of the burdens of collective obligations, and that such principle entails that each of us has the individual moral responsibility to make their fair contribution to herd immunity through vaccination. These individual moral obligations, in turn, entail a further individual obligation to support policies aimed at realizing herd immunity. The chapter concludes with a suggestion that the individual moral obligations to support such policies generate an institutional responsibility to implement them.
\end{abstract}

Keywords Vaccination $\bullet$ Herd immunity $\bullet$ Collective responsibility • Individual responsibility $\bullet$ Institutional responsibility

A. Giubilini, The Ethics of Vaccination, Palgrave Studies in Ethics and Public Policy, https://doi.org/10.1007/978-3-030-02068-2_2 


\section{Establishing Ethical Responsibilities in the Context OF VACCINATION}

This chapter is about the ethical obligations or responsibilities ${ }^{1}$ pertaining to vaccination of three different actors. As we shall see in more detail later, there are three possible bearers of ethical obligations: individuals, collectives, and institutions (such as states). Thus, one could ask whether any individual has a moral obligation to have themselves or their children vaccinated against common infectious diseases, such as the seasonal flu, mumps, measles, rubella, and any communicable diseases that pose major threats to the health and even survival of individuals. Alternatively, one could ask whether our community, as a collective, has a collective ethical obligation to realize herd immunity and what it means to have a collective obligation. Or, again, one could ask whether institutions have an ethical obligation to enforce policies that ensure a community's realization of herd immunity against certain diseases. Since I am looking for a philosophical justification for any such ethical obligation, the central parts of this chapter will be rather technical in philosophical terms.

Unsurprisingly, the fact that vaccination decisions need to be taken at three different levels - individual, collective, and institutional-generates conflicts of values within and between these levels. In particular, when grounding any ethical obligation to be vaccinated or to vaccinate one's children, and when legitimizing any coercive policy that forces individuals to vaccinate themselves or their children, a first ethical problem may arise from a conflict between individual best interest and individual autonomy. A second ethical problem may arise from a conflict between individual autonomy and public health. If my arguments are sound, I will, by the end of the chapter, have solved both problems and provided a philosophical justification for certain ethical obligations at each of the three levels. Before presenting this philosophical justification, however, let me say something more about the two ethical problems I have just mentioned, so as to give the reader a clearer view of the challenges ahead.

Let me start with the first problem, namely, the possible conflict between autonomy and best interest. With regard to child vaccination, one might think that it is quite uncontroversial to say that there is an individual ethical obligation to vaccinate one's children in order to protect their health: after all, being protected against an infectious disease seems

\footnotetext{
${ }^{1}$ From now on, I will use the terms "moral" and "ethical", as well as the terms "obligation" and "responsibility" (when referring to forward-looking responsibility), interchangeably.
} 
to be in a child's best interest, and parents have an ethical obligation to act in the best interest of their children, at least when doing so requires reasonable efforts and the interest being protected is deemed important enough (as seems to be the case for an interest in health preservation and as is certainly the case for an interest in survival). Unfortunately, it is more controversial than it might appear to argue that the best interest of a child can ground an ethical obligation to vaccinate one's children. For one thing, as we shall see in a moment, in certain circumstances it is not so clear that it is in a child's best interest to be vaccinated. Furthermore, even if vaccination is in a child's best interest, some parents might still claim that they have the right to make autonomous choices about their children's health and about what goes into their children's body. What I have just said about child vaccination applies a fortiori to adult vaccination. While in the case of child vaccination one might argue that parental refusal to vaccinate their children presents a conflict between a child's best interest and parents' right to make autonomous choices about their children's health, the same refusal in the case of adult vaccination does not seem as ethically problematic. At least according to contemporary liberal ethics, principles of self-determination and of bodily integrity outweighs any paternalistic consideration about a competent adult's best interest: if a competent adult autonomously decides not to be vaccinated, the fact that vaccination might be in her best interest does not seem to imply that the adult in question ought to be vaccinated or ought to be forced to be vaccinated. Besides, as was the case with child vaccination, it is not so clear that adult vaccination is always in the adult's best interest.

Since this last claim has probably raised an eyebrow or two, allow me to elucidate it. Of course, vaccine denialists do share the view that parents have a moral obligation to protect their children's health; however, as we have seen in the first chapter, they do not believe that vaccination sufficiently protects their children's health. While vaccine denialists undoubtedly overestimate the risks of vaccination, we have to concede that, as a matter of fact and for reasons different from the ones they defend, sometimes it is really not in a child's best interest to be vaccinated. How so? Even those of us who see vaccines favourably cannot deny the fact that vaccines can have side effects, some of which can occasionally be quite severe. Vaccine injury compensation funds (Mello 2008) adopted in many countries, such as the US and the UK (Looker and Kelly 2011) exist precisely because side effects can happen. For example, the MMR vaccine can cause anaphylactic reactions, and according to some controversial evidence (CDC 2018a). The seasonal flu vaccine can cause Guillain- 
Barre Syndrome (GBS), a serious autoimmune disorder that in its most serious forms can cause paralysis. Now, these possible side effects do not by themselves imply that vaccines are not safe and that they are not in children's best interest, given that their probability is extremely low and that it needs to be weighed against the probability of experiencing the severe, and sometimes lethal, consequences of infectious diseases. Anaphylactic reactions occur in less than one in a million individuals vaccinated with the MMR, but we need to consider that measles "can lead to serious complications such as pneumonia and encephalitis (inflammation of the brain). In addition, measles infection damages and suppresses the whole immune system", and "in high income regions of the world such as Western Europe, measles causes death in at least 1 in 5000 cases, but as many as 1 in 100 will die in the poorest regions of the world" (Oxford Vaccine Group 2016). Overall, then, there is wide consensus in the scientific community that "[g]etting MMR vaccine is much safer than getting measles, mumps or rubella" (CDC 2018a). The same goes for the seasonal flu vaccine. The risk of GBS is only one or two cases per million people vaccinated, but GBS can also occur, and actually is more common (though still very rare), after flu infections (CDC 2018b). Moreover, influenza kills between 290,000 and 650,000 people each year (WHO 2018). These considerations suggest that in spite of the risks, vaccination would often be safer than non-vaccination and would thus be in an individual's best interest. If there is a risk of measles pandemic, it is safer and rational for an individual to be vaccinated or to vaccinate her children against measles. However, there is a threshold of vaccination coverage rate in one's community after which the trade-off between risks of vaccination and risks of the vaccine-preventable infectious disease no longer favours vaccination. When a sufficiently large portion of the population (say, $99.99 \%$ ) is vaccinated, the risk of being infected becomes so low that it is outweighed by the very low risks associated with vaccination. More generally, the higher the proportion of vaccinated individuals in a given population, the lower the payoff for taking the risks associated with vaccination; and after a certain threshold, the risks associated with vaccination will necessarily be lower than the risks associated with the disease. In such circumstances, parents' moral obligation to act in the best interest of their children entails a moral obligation not to vaccinate them. Therefore, if the number of vaccine denialists is sufficiently small, they would be right - albeit for the wrong reasons - to claim that vaccination is not in their children's best interest. 
Let us move to the second ethical problem mentioned above, namely, the conflict between individual autonomy and public health. One could argue that the right to make autonomous decisions, including autonomous decisions over one's body, is limited by a harm principle: my liberty is not absolute, but is instead constrained by other people's equal liberty and other people's prima facie right not to be harmed by my behaviour. Indeed, it would be hard to find a reasonable ethical or political theory that does not endorse or at least is not consistent with the harm principle so formulated. At a first glance, the principle seems to apply to the case of vaccination, too: I do not have a right to autonomously decide not to vaccinate myself or my children because vaccine refusal could harm other people by exposing them to preventable infectious diseases. However, the situation might be more problematic than it might initially appear. For one thing, some people might object to the idea that there is a duty to protect other members of the community against diseases. They might believe that it would be a good thing to do so, but not that there is a moral obligation to do so, let alone that there should be a legal obligation or some other form of state coercion; for example, they might turn the argument based on the harm principle upside down and argue that what would be required of me in order to protect others would violate some of my fundamental rights (such as a right to bodily autonomy or bodily integrity). Furthermore - and more interestingly from a philosophical point of view-even assuming that there is an individual moral obligation to protect others against infectious diseases, some might deny that this obligation grounds an individual moral obligation to be vaccinated. The obligation might be collective (the meaning of which I will explain in greater detail later), but not individual. The reason is that one's contribution to herd immunity through individual vaccination is negligible. More specifically, one might argue that, where herd immunity exists, the moral obligation on each individual to be vaccinated would be weak, since the risk of infection for other people would be very small even if a single individual were not vaccinated (Dawson 2007, p. 171). And conversely, some have argued that where vaccination coverage rate is low, there is not much ground for a moral obligation to be vaccinated within a utilitarian perspective, considering that the risk that any other individual would be infected is high anyway, even if one decides to vaccinate (Verweij 2005, p. 329). Thus, that the moral obligation to be vaccinated is grounded in considerations of public health and on the harm principle is more controversial than it might initially appear. 
Having elucidated the main philosophical and ethical problems that arise when we want to ground ethical obligations with regard to vaccination behaviours, let us now turn to introducing the first two levels at which ethical obligations need to be established: the individual and the collective.

\section{Health, Rights, and Ethical Obligations}

All of us have some prima facie rights known as claim rights, that is, rights determining prima facie obligations that fall on other people. For example, we have a prima facie claim right not to be harmed by others, which generates a prima facie obligation on others not to harm us. This is an example of a negative right. Negative rights are the ones that give rise to negative duties, that is, moral obligations to abstain from doing something that could harm other people or that could prevent a certain benefit to other people. Positive rights, on the contrary, are the rights that give rise to positive duties, that is, moral obligations to do something in order to benefit someone or to prevent harm to someone. Other things being equal, positive duties (and rights) are rarer and more difficult to justify than negative duties (and rights). In other words, other things being equal, it is normally considered morally worse to cause harm by action (thus violating a negative duty) than to let the same type of harm happen by omission (thus violating a positive duty). The justification for the normative relevance of the act/omission distinction is a matter of moral theory and is beyond the scope of this book. If one sticks to the intuition that the act/omission distinction does have some normative relevance, one could argue that since vaccination is a positive action, then from a moral point of view, failing to be vaccinated or to vaccinate one's children is not the same as actively engaging in behaviours that harm or risk harming others. While there is a negative duty to refrain from the latter, some might argue that there is no positive duty to do the former, or at least the duty to do the former is significantly weaker. In particular, one could use the allegedly normative distinction between positive and negative duties to dismiss Jessica Flanigan's famous analogy between foregoing vaccination and randomly shooting a gun in the air (Flanigan 2014). According to Flanigan, the two behaviours are relevantly similar from a moral perspective, in that they both threaten other people's health and life. Therefore, according to her, in the same way as an authority has good reasons for prohibiting random gun firing, it also has equally good reasons for prohib- 
iting non-vaccination. One might appeal to the distinction between positive and negative rights and duties to dismiss this analogy: while randomly firing guns violates a negative duty, failing to be vaccinated or to vaccinate one's children would only represent a failure to act in order to benefit others and might therefore not give rise to any positive duty or positive right. Thus, within this perspective, failing to be vaccinated or to vaccinate one's child cannot be morally equivalent to actively putting other people's health and life at risk.

Is this response based on the act/omission distinction valid? I do not think so. Let us assume for the moment that any single non-vaccination does pose a significant risk to others, comparable to the risk posed by someone randomly firing a gun (as we will see below, this assumption is itself problematic). There are reasons to resist the conclusion that failing to vaccinate a child is, as an inaction, less bad than actively doing something that threatens other people's health and life. More can be said in support of the idea that failing to be vaccinated or to vaccinate one's children does represent a failure to fulfil a stringent moral duty, even if it is only a positive duty. After all, Flanigan might be onto something with her analogy. The fact is that the normative force of the act/omission distinction, even if intuitively valid in most circumstances, does not seem to retain its intuitive and normative force in all circumstances. One likely explanation for the intuitive attribution of normative relevance to the act/ omission distinction is that, quite obviously, it is often easier to do nothing than to do something. Therefore, when the same types of outcomes are considered, such as the generation of a certain harm or risk of harm to others, the obligation to refrain from doing something that could harm others seems more stringent than the obligation to do something in order to avoid possible harm to others: the easier it is for me to prevent a certain risk of harm, the fewer excuses I have for failing to prevent it. But if the intuitive normative force of the act/omission distinction is indeed explained by the relative higher demandingness of actions over omissions, it follows that the easier and less demanding an action is, the closer a failure to take that action in order to prevent harm to others comes to actively harming others, morally speaking, when the same type of harm is considered. In other words, when the actions required to avoid possible harm to others are sufficiently easy and costless, positive duties become morally equivalent to negative duties. Failing to take action and thus to fulfil a positive duty would be significantly similar, from a moral point of view, to the violation of a negative duty. 
The idea I have just formulated is sometimes referred to, more simply and more intuitively, with the term "duty of easy rescue": positive duties of "easy rescue" can be as compelling as negative duties, both ethically and legally (Savulescu 2007). For the moment, let us confine ourselves to the ethical dimension. To recall Peter Singer's famous thought experiment, if I see a child drowning in a pond whom I could easily save at a comparatively small cost to me (e.g., at the cost of ruining my new pair of shoes), then I have a moral obligation to save the child (Singer 1972), even if the obligation is an instance of a positive, and not of a negative, duty. The child has a positive right to be saved, considering how comparatively easy and costless it is for me to save her. Tim Scanlon made the duty of easy rescue even less demanding by stating that we have an uncontroversial moral duty to do something that involves a slight or moderate sacrifice (in absolute, not in comparative terms) and that can prevent something very bad from happening (Scanlon 1998, p. 224)—a formulation that, unlike the Singerian one, does not entail that we have a moral duty to do something that is very costly to us if the outcome to be prevented is comparatively very bad. Here, to make my point as uncontroversial as possible, I will stick with Scanlon's less demanding formulation. What I want to point out is that since vaccination entails a very small cost to individuals and a very large benefit to others in terms of disease prevention, there is a duty of easy rescue to be vaccinated, even if it is a positive duty, in order to protect the categories of vulnerable individuals I have mentioned in the previous chapter. If non-vaccination harms or risks harming others, then failing to vaccinate is as bad as positively doing something that harms or risks harming others, as Flanigan's analogy suggests.

But we need to be careful here. As I have noted earlier, the contribution of each individual vaccination to herd immunity is negligible. It is true that if a non-vaccinated individual does infect another individual, then the non-vaccinated individual would be causally and morally responsible for the harm caused to the other (Giubilini et al. 2018) or at least the individual's carers would be. However, as suggested above, where herd immunity does exist, it is very unlikely that a non-vaccinated individual would infect another one; and where vaccination rates are extremely low, a nonvaccinated individual would not make a significant difference to the risk of another individual being infected-if she does not infect a specific individual, someone else probably will and epidemics will occur. The risk that a non-vaccinated individual would actually make a significant difference to the chances that another individual is harmed is therefore significant only if vaccination rates in one's community are within a certain specific 
range, neither too high nor too low. Only in such cases an individual duty of easy rescue applies and morally requires individuals to be vaccinated. However, if we want to ground an unconditional moral obligation for any individual to be vaccinated (except, of course, in the case of medical contraindications), and not just an obligation that is dependent on a contingent risk of harming others, we need to find some other form of moral justification. Does this justification exist? I will argue that it does.

Let us start from the existence of an individual's prima facie claim right not to be infected by a vaccine-preventable disease, when this can be achieved through vaccinations. If an individual cannot be vaccinated, or if a vaccine is not effective in an individual (no vaccine is $100 \%$ effective), who is the bearer of the corresponding moral duty not to harm, either by act or omission, the vulnerable individual? Sometimes the obligations corresponding to certain individual rights cannot be fulfilled by individuals, but only by collectives. This is the case with the individual right to be protected from vaccine-preventable infectious diseases: since it is only the public good of herd immunity that can guarantee a sufficiently high level of protection, the obligation in question is the obligation to realize herd immunity. And the realization of herd immunity can only be a matter of collective responsibility (Giubilini et al. 2018). As put by Robert Goodin, "responsibilities get collectivized simply because that is the only realistic way (...) of discharging them" (Goodin 1998, p. 55).

A classic example in the philosophical literature of collectivized responsibilities is Parfit's "Harmless Torturers" case, where each torturer contributes only negligibly to the pain experienced by the victims, but the victims feel pain as a result of the contributions of a sufficiently high number of torturers (Parfit 1984, p. 81). Also in such case, the moral obligation not to inflict pain is collective, and not individual, since by hypothesis each individual torturer is "harmless". But what does it mean to have a collective obligation? Who or what, exactly, is the bearer of this obligation, and what does a collective obligation imply for individual obligations? In the remaining of this chapter, I will attempt to answer such questions.

\section{Aggregate Collective Responsibility and Herd IMMUNITY}

In what sense can a collective be responsible or have a collective moral obligation? In particular, I am referring here to the responsibilities of the communities that can realize herd immunity, and therefore of unstruc- 
tured, loose collections of individuals, rather than the responsibilities of organized, structured groups that can be assimilated to individual agents (List and Pettit 2011). Also, in principle and in an ideal world, the collective in question would have to include the entire global population, because local failures to realize herd immunity could endanger the life or health of the vulnerable people living in a certain area. Therefore, ideally, the type of collective obligation we are looking for would have to be what Bill Wringe called a "global obligation" (Wringe 2014). However, in many areas of the world, and in developing countries especially, access to vaccines can be both very difficult and very expensive. It seems unreasonable to expect that people in poor countries who do not have access to vaccines have a collective moral obligation to contribute to the realization of herd immunity. I will proceed under the assumption that the collective obligation to realize herd immunity, although in principle a "global obligation", given the situation of our world, currently only applies to the group of people with easy access to vaccines.

Now, if it is true that the obligation to realize herd immunity cannot be individual, it also seems problematic to argue that there exists a collective to which such responsibilities can be attributed. Some authors, for example Peter French (1984), have argued that only collectives with a formal decision structure can be the subjects of collective obligations. These types of groups constitute collective entities that, because of their internal structure and decision procedures, count as particular types of agents and therefore might bear a form of responsibility (as some have argued, including Pettit 2007, and List and Pettit 2011). However, people who together have the causal power to realize herd immunity constitute simply a random collection of individuals. There is no structured and formal connection or coordination among individuals that render them a collective agent. And to the extent that we think that only agents, that is, individuals that can intentionally act, can have the responsibility to act in certain ways, the collective that could realize herd immunity cannot have the moral responsibility to realize herd immunity, at least not in the same sense as agents like a state or a corporation have the responsibility to bring about or prevent certain outcomes. Attribution of collective responsibility to unstructured groups might reflect some form of metaphorical talking, but it is difficult to see how collective responsibility can literally be attributed to such groups.

However, according to some, it is not necessary that a group has a structure and an internal organization in order to be considered an agent and therefore a subject of collective obligations. As Sean Aas has suggested, 
when individuals are prepared to do their part in a collective enterprise "were they to become sufficiently sure that others will do their part as well" (Aas 2015, p. 13), then it makes sense to say that the collective, rather than its individual members, is doing something; hence, the collective amounts to an agent that is, in turn, subject to collective obligations (Aas 2015). However, whether or not this position is philosophically sound, the collective that can realize herd immunity through a large enough number of individual members being vaccinated clearly is not an agent in this sense either: typically, as we have seen in Chap. 1, individuals do not decide whether to be vaccinated or to vaccinate their children on the basis of a belief as to whether others will be vaccinated as well, and therefore they do not form a collective agent in Aas' sense either-although, as we shall see in Chap. 4, the assurance that other people around them are vaccinated removes a psychological barrier to choosing to vaccinate.

According to another view, collective obligations can be characterized as "joint obligations that are jointly owned by [individual] agents together" (Pinkert 2014, p. 189). For example, the obligation to form a circle by definition requires the joint effort of a plurality of subjects, since no individual can by herself form a circle. In this respect, the obligation to realize herd immunity is analogous to the obligation to form a circle, that is, it is a joint obligation. But what kind of agent can be the bearer of joint obligations? According to those who endorse the "joint obligation" understanding of collective responsibility or collective obligations, joint obligations could be attributed only to individuals who can engage in joint actions. By "joint actions", Felix Pinkert means "things that a plurality of agents do together, for example, to form a circle, independent of whether or not they have any specific joint intentions" (Pinkert 2014, p. 191). However, this definition is problematic: forming a circle does seem to require a specific joint intention to form a circle, as a random collection of individuals is unlikely to form a circle as a result of random individual behaviours of its member. More in general, it is difficult to see how something can qualify as a "joint action" without some form of joint or shared intention, that is, the intention to take part in a shared enterprise on the common understanding that everybody else is doing their part as well (this is a very simplified definition of the notion of "shared intention" as presented in a way more sophisticated way by Michael Bratman (1993, p. 106)). However, as I have mentioned in the previous paragraph, realizing herd immunity does not require any joint intention or coordinated action by individual members of a collective. In this respect, realizing herd immunity is different from performing a joint action. Therefore, it is at least 
problematic to say that the collective obligation to realize herd immunity can be conceptualized as a joint obligation in the sense just presented, if it is true that being subject to joint obligations requires that the individuals of the collective engage in joint actions and if it is true that joint actions, such as forming a circle, require the joint intention and the coordinated efforts of individuals.

And indeed, on Anne Schwenkenbecher's account of joint actions, such actions do presuppose a "joint goal" and "a condition of mutual belief and knowledge regarding other people's contributions to that goal: People who act jointly with others do so because they believe that these others will contribute their share towards the joint goal" (Schwenkenbecher 2013 , p. 313). This account closely resembles Aas' aforementioned condition for the existence of collective agents who can be the bearers of collective obligations. But, once again, individuals jointly realizing herd immunity by being individually vaccinated do not typically engage in joint actions in neither of the senses just presented. Indeed, Schwenkenbecher convincingly argues that there is an important difference between cases of individuals capable of engaging in joint actions, which can be subjects to "joint duties" to engage in joint actions, and a type of case analogous to the realization of herd immunity, namely, collectively reducing carbon footprint, which requires that a large number of individuals reduce their individual emission (in the same way as realizing herd immunity requires that a large number of individuals be vaccinated). For one, on Schwenkenbecher's account, "joint action of individuals in groups that are not group agents works best on small to medium scale" (Schwenkenbecher 2013 , p. 321), rather than on large scales; thus, even if realizing herd immunity required a joint action, this action would be almost impossible to be carried out, since it would require the cooperation of a very large number of individuals. In addition, and more importantly, mitigating global warming or realizing herd immunity does not require joint actions but only aggregate individual actions. The only situation in which mitigation of global warming or realization of herd immunity would presuppose joint actions, and therefore would be the object of joint duties, would be if the potential contributors to the collective effects were part of a movement where individuals can be thought to share the intention to realize the collective effect and therefore to be acting on the basis of the beliefs that others will contribute as well. We can think-so Schwenkenbecher suggests - of the hypothetical organization that she dubs "Citizens for Climate Change Mitigation" (Schwenkenbecher 2013, p. 315) or, we might propose, a hypothetical "Citizens for the Realization of Herd 
Immunity". Since such organizations do not exist in our world—although one might wish that they did, and perhaps the case of the highschool class discussed in Chap. 1 is an example of this - there can be no joint duty to mitigate climate change or to realize herd immunity as things stand now. Thus, the collective obligation to realize herd immunity cannot be conceptualized in terms of a "joint duty" either.

So far, it seems that the obligation to realize herd immunity can be neither genuinely collective, since there is no plausible understanding of collective responsibility that can be attributed to a loose, unstructured collection of individuals; nor individual, since it is not in any individuals' power to realize herd immunity. And yet, if we want to claim that individuals have certain prima facie claim rights (particularly the right to be protected from vaccine-preventable infectious diseases), and if the necessary condition for someone to be protected from infectious disease is that herd immunity from a certain disease is realized, we need to be able to say that there is someone or some entity bearing the corresponding moral obligation.

Some scholars have advanced the idea that when there clearly is a desirable collective outcome but apparently no actual organized or goaloriented collective entity that could realize it, there is nonetheless a collective agent that might be the bearer of some form of collective moral responsibility. Such a collective agent is merely potential, or putative, rather than actual (May 1998; Isaacs 2011, 2014)—and what this means will be explained in a moment. However, this feature does not exclude that it could be a bearer of putative or potential moral obligations that have the same implications in terms of attribution of moral responsibility to its members as actual collective obligations of actual collective agents do. Let us analyse in some more details, then, the idea that there are putative group agents with the putative collective obligation to realize herd immunity.

A merely putative group agent is formed by the random collection of individuals that could turn themselves into an organized group or a goaloriented group in a way that is obvious and clear to a reasonable person (Held 1970; Isaacs 2011, p. 153), that is, into something that can be considered a collective moral agent, in order to fulfil the putative or potential collective obligation to realize a certain collective outcome as a group agent (Isaacs 2014). Not all random collections are also putative group agents. That the course of action required of the collective must be obvious to the reasonable person (in order for the collective to be a putative group agent with a putative collective obligation) is a necessary qualification in order to 
avoid the paradoxical implication that any random collection of individuals (e.g., the one formed by me, someone living in Nepal, and the father of a friend of mine) can be the subject of putative collective obligations (Isaacs 2011 , p. 153). Importantly, putative group agents are distinct from mere random collections because the former, unlike the latter, having the potential to turn themselves into organized groups, can also have the moral duty to form a group agent (Collins 2013). Hence, there are two types of collective moral duties that can be attributed to putative group agents: the duty to turn themselves into an actual organized or goal-oriented group and the duty to perform, as a group, the coordinated action that will realize the outcome that they have an obligation to realize. When a merely putative collective agent fails to turn itself into an actual organized group, that is, into an actual group agent, in order to fulfil a putative collective obligation, it can be held morally blameworthy or retrospectively responsible for its "collective inaction" (May 1990).

An example will help clarify in what sense merely putative group agents can be bearers of putative collective moral obligations. Consider Tracy Isaacs' "coordinated bystander" case (Isaacs 2011, p. 144): in Isaacs' example, four bystanders see six children on a raft hurtling towards a waterfall. They can only save the children through an obvious (to the reasonable person) course of action requiring them to coordinate among themselves; any individual acting in isolation would not be able to save the children. In such cases, it is clear (to the reasonable person) that the individuals ought to act together to save the children by turning themselves into a group that could take action. We can therefore say that the collective is a putative group agent with a putative collective obligation to organize itself in order to save the children.

According to Isaacs, many of the global challenges we face today, such as global poverty, hunger, and climate change, require collective actions by agents that are merely putative group agents (Isaacs 2014, p. 43). Assuming, for the sake of argument, that this is true, the question is: could we include in the category of putative group agents the collective of individuals who together could prevent or contain the spread of infectious disease by realizing herd immunity? The answer has to be negative: what is required in order to realize herd immunity is that individuals engage in aggregate individual actions, rather than in coordinated group actions. Only by being aggregately vaccinated can a large enough group of individuals realize herd immunity. Thus, even if Isaacs claims that global problems that seem analogous to the realization of herd immunity, such as 
climate change, raise putative collective obligations, we can conclude that the notion of putative collective obligation attributable to putative group agents also fails to account for the type of collective obligation entailed by the duty to realize herd immunity.

Thus, we have seen that the characterization of collective obligations as obligations of structured groups, as joint obligations, and as putative collective obligations cannot account for the type of collective obligation that falls on the collective of individuals that can and ought to realize herd immunity. Should we accept the idea that no existing account of collective obligation can be applied to the collective obligation to realize herd immunity and, therefore, that there can be no positive moral duty to realize herd immunity, given that there is no one to whom we can attribute such duty? It seems that the answer would have to be affirmative. However, if so, the only remaining alternative understanding of collective obligation is the one according to which the obligation to realize herd immunity is collective in the merely aggregative sense, that is, in the sense that each and every individual member of the collective with the power to realize herd immunity has a moral obligation to contribute to the realization of the collective effect. However, this conception of collective responsibility has problems of its own, because it would imply attributing moral obligations to individuals even when any one of them fulfilling such obligation would not have any significant impact on, and therefore would not substantially contribute to, the collective outcome.

In sum, it seems we are facing an insurmountable conceptual problem, but one with relevant practical implications: neither individuals nor collectives can be attributed moral obligations to protect vulnerable individuals from vaccine-preventable infectious diseases; therefore, no one seems to be under any moral obligation to be vaccinated. However, such problems are not insurmountable. In the next two sections, I will explain, through a metaphysical (section "Aggregate Collective Responsibility and Herd Immunity") and an ethical (section "From Collective to Individual Responsibility: The Metaphysical Arguments") analysis of the relationship between collective and individual obligations, why individuals are under a moral obligation to contribute to herd immunity even when their contribution would be insignificant.

For the moment, I would like to introduce a new label for the peculiar collective character of the moral obligation to realize herd immunity. I will use the expression aggregative collective obligation in order to emphasize the "deflationary" sense of "collective" here involved, that is, that 
the collective in question is not to be understood as an independent entity irreducible to the aggregate of its constituent individuals. In other words, collectives have an obligation to realize herd immunity in the sense that the collective obligation is fulfilled through the aggregate actions of the collective members. An alternative, though less explicative way of referring to aggregative collective obligation as I understand it here is the one adopted by Gunnar Björnsson (2014). According to Björnsson's terminology, we can say that the collective obligation to realize herd immunity is "essentially shared" by certain individuals. Essentially shared obligations can be considered a particular type of collective obligations attributable to any groups that can and ought to realize certain outcomes through aggregate individual actions, rather than through coordinated group actions. As put by Björnsson, "shared obligations are not necessarily obligations to perform joint actions" (Björnsson 2014, p. 109) and "a shared obligation can be fulfilled without any sense of coordinated or shared agency among the parties" (Björnsson 2014, pp. 109-110). In other words, a shared obligation can be fulfilled when members of a certain collective engage in a certain behaviour in such a way that a certain collective outcome, for example, herd immunity, is realized. Thus, we can say that there is a shared obligation to realize herd immunity or an aggregative collective obligation to realize herd immunity.

The next question I want to address is what this type of collective obligation entails for attribution of individual obligations to be vaccinated (the metaphysical account of the relationship between collective and individual responsibility, presented in the next section), and why the collective obligation to realize herd immunity translates into an individual obligation to be vaccinated to which all members of a collective are subject (the ethical account of the relationship between collective and individual responsibility, which I will present in section "From Collective to Individual Responsibility: The Ethical Argument”).

\section{From Collective to Individual Responsibility: The Metaphysical Arguments}

So far, I have established the existence of a shared or aggregative collective obligation to realize herd immunity. The next question I want to ask is what such collective obligation implies in terms of individual obligations. Most of the arguments about the existence of collective obligations of loose collections and the relationship between collective and individual 
responsibility can be characterized as metaphysical arguments: they concern the issue as to what makes an obligation "collective" and the nature of the relationship between such collective obligations and the individual obligations of the collective's constituent members. Without the presumption of exhaustiveness, I will present in this section some of the metaphysical conceptions of collective obligation and of its relation with individual obligations. I will apply these considerations to the case of the collective obligation to realize herd immunity and its relation to the individual obligation to be vaccinated.

Let us start with the case of the trapped man, discussed by Virginia Held (1970). In her example, three pedestrians notice a man trapped under a collapsed building. They can save the man by removing the beams that keep him trapped. However, they fail to organize as a collective and to decide which beam to remove first; as a consequence, the trapped man dies. According to Held, the three men are collectively morally responsible for failing to form an organized group that could have saved the trapped man. This example is taken by Held to show that collective responsibility of random collections is simply distributive: each individual is individually responsible for the group's failure. As put by Held, "if random collection $R$ is morally responsible for the failure to do $A$, then every member of $R$ is morally responsible for the failure to do $A$, although, perhaps, in significantly different proportions" (Held 1970, p. 480). Held applied this principle of distributive collective responsibility to the case of backward-looking responsibility. However, the same principle can be applied to future-looking moral responsibility, that is, moral obligations. Consider, for instance, the analogous "coordinated bystander" case discussed by Tracy Isaacs (2011, 2014), which we have presented above. According to Isaacs, the putative collective obligation has "exactly the same ordering and mediating potential for individual action that an actual collective obligation would" (Isaacs 2011, p. 150). In cases like this, it is clear (to the reasonable person) what the group should do in order to save the children, so the group agent has the putative collective obligation to save the children. In virtue of this putative collective obligation, Isaacs argues, each individual has a moral obligation to do her part (Isaacs 2011 , p. 151) to contribute to the fulfilment of the putative collective obligation. As Isaacs put it, "this putative collective obligation (...) is a starting point for bridging the apparent gap between seemingly inconsequential individual contributions and new understandings of the part they play in more powerful collective undertakings" (Isaacs 2011, pp. 151-152). 
Granted, when we talk of the collective obligation to realize herd immunity, the kind of collective obligation with which we are concerned is, as noted earlier, not a putative collective obligation, but a shared or aggregative collective obligation. However, Isaacs' account of the relationship between the collective and the individual responsibility does not depend on the putative character of the collective obligation in question, but is instead based on the relationship between what can be realized collectively and the obligation of the individuals within the collective to do what is required in order for the collective effect to obtain. Therefore, the same principle bridging collective and individual obligation can be applied to the case of aggregative collective obligations. To use an example which is different from the one introduced by Isaacs but which is analogous to the aggregative type of collective obligation involved in the case of realization of herd immunity, consider an individual's failure to contribute to the prevention of global warming, for example, by avoiding driving just for fun. Such failure makes the individual blameworthy because it is a failure to "do her part in a collective action that could solve global warming" (Isaacs 2011, p. 151). The action here is collective in the same sense in which the action required to realize herd immunity is collective: the "collective action" consists of individual aggregate actions. In such cases, according to Isaacs, the failure to make one's contribution to the desirable collective outcome is "not morally excusable because it is mediated by the putative collective obligation to solve global warming" (Isaacs 2011, p. 151); more precisely, to use the terminology we have introduced, it is mediated by the shared or the aggregative collective obligation to solve global warming. In the same way, we might say that the failure to contribute to herd immunity by being vaccinated is not morally excusable because it is mediated by the shared or aggregative collective obligation to realize herd immunity. So it seems that we have established not only a form of shared or aggregative collective moral obligation to realize herd immunity but also an individual obligation to make a contribution to the realization of herd immunity. And as Isaacs explains, "being a possible member of a group that could effectively take action to address an obvious issue that needs addressing can influence a person's individual moral obligations" (Isaacs 2014, p. 57).

Let us consider now a different account of the metaphysical relationship between collective and individual obligations. This is the account put forward by Bill Wringe. According to Wringe, collective obligations of unstructured, loose collectives are explanatorily and ontologically more 
fundamental than the obligations of individual members of the collective: the former can be used to explain the existence of the latter. As Wringe put it, "it is part of the moral phenomenology that the individual obligations of A and B can be explained by reference to the existence of a collective obligation and by A and B's membership of the relevant collective" (Wringe 2016, p. 485). Moreover, as Wringe argues elsewhere, "it seems plausible that a claim about the obligations of a collective of which I am a member could have a legitimate influence on me in deciding (or perhaps better, could be a reason relevant to deciding) how to respond to a situation which appears to call for a collective action" (Wringe 2010, p. 226). Such relationships between collective and individual obligations can be explained by distinguishing, as Wringe (2016, pp. 224-225) does, between the subjects and the addressees of collective obligations. The subjects of a collective obligation are those to whom the obligation applies, which might be collectives, such as the collective with the potential for realizing herd immunity. The addressees of collective obligations are those whose capacity for deliberation is affected by the existence of the collective obligations, namely, individual members of the collective, such as the individuals who can contribute to herd immunity by being vaccinated. In this view, the individual addressees of a collective obligation "acquire obligations to do things which are appropriately related to the carrying out of the action whose performance would constitute fulfilment of the collective obligation" (Wringe 2010, p. 227). If we extend the same point to shared or aggregative obligations, we could say that, for instance, individual members of collectives with a shared obligation to realize herd immunity, as addressees of the obligation, acquire the individual obligation to do what allow the collective to fulfil the obligation, namely, being vaccinated.

Wringe has formalized the principle connecting collective to individual obligations, that is, the "global supervenience" of collective over individual obligations, as follows:

If in a particular situation a collective $\mathrm{C}$ has an all-out obligation to Phi, then, for any member $\mathrm{M}$ of $\mathrm{C}$, and for any set $\mathrm{S}$ of possible actions of members of $\mathrm{C}$ that, if performed together, would constitute C's Phi-ing, if S includes M's doing $\mathrm{A}$, then $\mathrm{M}$ has a pro tanto obligation to do A provided that (a) the other members of $\mathrm{C}$ are doing or are reasonably likely to do the actions assigned to them in $S$ or they would be reasonably likely to do these things if $M$ were to do A and (b) M's doing A does not by itself make it less likely that C will Phi. (Wringe 2016, p. 488) 
The formulation is rather (perhaps unnecessarily) convoluted, but with a small effort we can see how the principle applies to the cases we are interested in here by replacing "phi" with realizing herd immunity and " $\mathrm{A}$ " with being vaccinated. The fact that individual contributions represent the only means through which collectives can fulfil their obligations (Wringe 2016 , p. 489) suggests that once we have established that there are collective obligations, such obligations generate obligations for individual members to contribute to the collective effect: there is no other way a collective obligation can be fulfilled except through each individual doing their part (Wringe 2014, p. 180). We can call this the "means argument" for the existence of individual obligations to contribute to collective enterprises.

However, the metaphysical accounts of the relationship between collective and individual obligations I have presented here do not address, let alone answer, the question of why a shared or aggregative obligation is supposed to generate an individual obligation that applies to each and every individual member of the collective. The question becomes particularly pressing in light of the fact that any individual vaccination is likely to be neither sufficient nor necessary for the fulfilment of the collective obligation to realize herd immunity. To address and answer this type of question, we need an ethical analysis of why a collective obligation generates individual obligations. This will be the subject of the next section.

\section{From Collective to Individual Responsibility: The Ethical Argument}

At least in some cases, if everyone contributed to some collective effect, the effect would be over-determined. This makes it difficult to claim that each and every individual in those cases has a moral obligation to contribute. Realization of herd immunity is one such case. It seems therefore possible to question the idea, which I have introduced in the previous section, that collective obligations to realize herd immunity give rise, by their very own nature, to individual obligations to contribute to herd immunity by being vaccinated. As put by Felix Pinkert, individual obligations of the form "you ought to contribute" in the context of collective obligations "imply that you ought to contribute even if not enough others contribute as well, but it is implausible that one ought to perform such pointless actions. In a more sophisticated form, 'you ought to contribute if enough others contribute as well', it turns out that everyone discharges their obligation if no one contributes" (Pinkert 2014, p. 189), which seems absurd. 
According to Isaacs, the fact that each individual contribution would make no difference to the prevention of global warming does not rule out that individuals have a moral obligation to contribute to the prevention of global warming (Isaacs 2011, p. 151). The same seems to follow if we apply Wringe's principle connecting collective and individual responsibility to the case of global warming. Presumably, then, Isaacs and Wringe would say the same about individual contributions to herd immunity: in all such cases, they would say that the collective obligation mediates individual obligations. But why would any individual have a moral obligation to make an irrelevant contribution to an important good? Something clearly needs to be added to their account in order to explain how an individual obligation to make an irrelevant contribution can derive from a shared or aggregative collective obligation. In this section I am going to provide what I think is the missing piece of the puzzle, which involves ethical considerations about how the burdens of a collective, or aggregative, or shared obligation ought to be shared.

Indeed, also in Björnsson's account of essentially shared obligations, there is a problematic relationship between the collective (shared) obligations and individual obligations of members of the collective. One example of shared obligation he provides is that of three people who are polluting a lake by using a certain solvent to paint their boats, which is killing the fish in the lake. The fish could be saved only if at least two of them stopped polluting, but not if only one stopped. According to Björnsson, there is in this case a shared obligation to stop polluting, in the sense that the obligation to stop polluting can be fulfilled by individuals behaving in a certain way that does not require shared intention or coordinated actions. Like the case of herd immunity, this is a situation in which the realization of the desirable collective outcome (saving the fish or realizing herd immunity) depends not on what any single individual does, but on what the other members of the collective do: anyone's contribution to the collective effect is insufficient to realize the desirable collective effect. Where one's contribution to the collective outcome is not sufficient for the collective outcome to occur, there is a mismatch "between reasons underlying the shared obligation and individual reasons to contribute to its fulfilment" (Björnsson 2014, p. 108). Thus, the account of shared responsibility endorsed here "makes it intelligible that a group has an obligation even though no individual agent has an obligation to contribute" (Björnsson 2014, p. 118). In other words, relying merely on a metaphysical account of collective obligation and of its relationship with individual 
obligation leaves us with a situation wherein the collective obligation to realize herd immunity is insufficient to warrant the existence of any individual obligation.

If all this is true, then we need a separate argument for why shared obligations generate individual responsibilities for the members of collectives with the causal power to realize herd immunity. The argument I am going to provide is a fairly simple and straightforward one, based on considerations of fairness in the distribution of the burdens that a shared or aggregative collective obligation entails. Once we assume that there is some kind of collective obligation to bring about a certain desirable outcome, we also have to assume that there arise a certain amount of individual moral obligations that need to be fulfilled in order for the collective or shared obligation to be fulfilled in turn. After all, as mentioned earlier, fulfilling individual obligations to contribute to the collective effect is the only means through which the collective obligation can be fulfilled. Thus, the collective obligation to realize herd immunity generates a certain amount of "burdens": a certain number of individuals will have to be vaccinated. I call vaccination "a burden" in this context because some people are opposed to it and because vaccination does involve some small inconvenience (possible temporary pain of the injection, having to pay a visit to the doctor, potentially a financial cost, minor risk of some side effects, etc.). That said, we need to bear in mind that vaccination also, and indeed primarily, benefits the individual who is vaccinated by giving her immunity from infectious diseases. All in all, vaccination involves very light and certainly bearable individual burdens, which can be vastly outweighed by the individual benefits it entails. In any case, the relevant question, for our purposes, is the question as to how such burdens should be distributed among individuals who form the collective with the moral obligation to realize herd immunity. It is safe to assume that such burdens should be distributed fairly, to the extent that we think that fairness is an important value that needs to be taken into account when distributing any kind of burden involved in the realization of important public goods. Thus, fairness demands that each individual does whatever she reasonably can in order to contribute to the fulfilment of the collective or shared obligation, regardless of the actual impact any individual action would have on the realization of the collective outcome. In other words, fairness requires that any individual who has the capacity to reasonably bear such burdens makes her fair contribution to the fulfilment of the collective obligation. For instance, in the case of realizing herd immunity, the group of people with 
the individual obligation to accept a fair share of the burdens will include any individual who does not have any medical condition that would make vaccination supererogatory, or who is not too young or too old to be vaccinated (Giubilini et al. 2018).

This also means that it would be unfair to require those for whom vaccination would be supererogatory to make their contribution to herd immunity. Such request would not be fair because the burden these individuals would have to bear if they were vaccinated would be much greater than the burden borne by other individuals. Individuals who are either immunosuppressed, allergic to vaccination, or too young or old to be vaccinated do not have a fairness-based moral obligation to contribute to the fulfilment of the collective obligation to realize herd immunity. Indeed, they are the very individuals who ought to be protected from the threat of infectious diseases by making sure that enough people around them are vaccinated.

Thus, fairness provides that missing link between aggregative and individual responsibility as discussed earlier: we can say that it is because of a requirement of fairness that a shared or aggregative collective obligation generates individual moral obligations such as the individual moral obligation to be vaccinated. Since considerations of fairness are not primarily about the impact of one's behaviour on others, but about distribution of benefits and costs, they ground an individual moral obligation to be vaccinated even if any individual vaccination would have no significant impact on vaccine coverage rates and on reducing the risk of infection for other people.

One last problem that needs to be addressed when attributing individual responsibilities for vaccination is that often vaccination decisions concern children, not adults, and that it seems problematic to argue that children have fairness-based moral obligations to be vaccinated. Plausibly, one needs to be a competent moral agent in order to be subject to a moral obligation, and children are not competent moral agents at the age at which most vaccinations are typically recommended: simply, they do not have the adequate level of understanding to make informed decisions and to take responsibility. There are exceptions, though: vaccines against meningococcal groups A, C, W, and Y disease are usually recommended for 12-year-old children, who arguably do count as moral agents and are subject to moral obligations. In such cases, the argument for an individual moral obligation to be vaccinated applies directly to such children. What about younger children and infants? Here, the moral obligation in ques- 
tion is not that of being vaccinated, but that of vaccinating one's children. Since young children cannot take responsibility for their actions, it is parents who have to take responsibility on their behalf: parents have a fairnessbased obligation to make their fair contribution to herd immunity by vaccinating their children. Not all moral obligations that parents have, as parents, are directed to the best interest of their children. Vaccination is one example: although vaccinating one's children would often promote their best interest, there is a moral obligation to vaccinate one's children that is not grounded in a duty to promote their best interest, but in a duty of fairness towards society. To the extent that parents can, should, and do make decisions on behalf of their children, they also can make moral decisions on behalf of their children, as they in fact often do in many other contexts.

\section{From Individual to Institutional Responsibility}

So far, I have argued that the existence of a collective obligation to realize herd immunity, together with a principle of fairness in the distribution of certain burdens, generates an individual moral obligation on each individual member of the collective to make her contribution to herd immunity. But what does it mean, exactly, to make one's contribution to herd immunity? As we have seen, it certainly means to be vaccinated and to vaccinate one's children against the infectious diseases from which individuals have a prima facie claim right to be protected.

But this cannot be the end of the story. In order for the collective obligation to be fulfilled, it is necessary that enough individuals be vaccinated and not just that any single individual is vaccinated. In other words, there are individual obligations and there is the collective obligation, but the collective obligation consists in an obligation that a certain minimum number of individuals are vaccinated, and therefore the contribution each individual ought to make is towards this end. Therefore, the question arises as to whether the contribution any individual ought to make should include doing something that makes it the case, or at least makes it more likely, that enough other people are vaccinated as well. If doing so comes at small or reasonable cost to the individual, then it seems that fairness requires that the individual makes this type of contribution, too. By "reasonable", I mean here something that does not involve a too large cost to the individual, consistent with the duty of easy rescue I have discussed previously. 
The traditional or common-sense understanding of moral responsibility is an individualistic understanding whereby moral responsibility only has implications for individual behaviour. But this traditional conception does not provide a satisfactory answer to the question of what an individual ought reasonably to do in order to contribute to the fulfilment of a collective obligation. Taking seriously the role of the collective nature of certain responsibilities in shaping individual moral responsibilities requires going beyond this common-sense individualistic account of responsibility, and embracing what we might call a "political" understanding of moral responsibility: individual responsibility, in contexts of collective responsibility, is a responsibility to do what one reasonably can to ensure that other people also make their contribution to the desirable collective outcome, for example, to herd immunity.

But what does this mean in practice? How can an individual reasonably contribute to ensuring that the threshold for herd immunity is reached? We can be sure that enough individuals are vaccinated when there are effective vaccination policies in place-and which policies exactly are required depends on what level of state coercion is necessary to realize herd immunity, an issue I will address in the next chapter. Thus, an individual can reasonably contribute to ensuring that enough others do their part by supporting the adequate forms of organization and policies. This means that an individual obligation to make her contribution to a desirable collective outcome entails a prima facie individual obligation to support policies that ensure the contribution of a sufficient number of others as well. To support effective vaccination policies means, at the very least, to refrain from hindering the implementation of such policies; thus, for example, protesting against mandatory vaccination, or requesting exemptions from mandatory vaccination, means failing to fulfil one's moral obligation to do what one reasonably can to ensure that herd immunity is realized and that members of one's community are protected from infectious disease. But to support effective vaccination policies also means to urge governments to implement such policies where they are not in place and herd immunity does not exist yet.

Since individuals have a moral duty to support effective vaccination policies, a democratic state has the strongest justification possible for implementing such policies, at least if we accept the rather uncontroversial principle that the legitimization for public policies in democratic states derives from individuals' support. Even where individuals do not actually support vaccination policies, the fact that they ought to support them makes those policies morally legitimate. 
In discussing the problem of what should be done to counteract global warming, Walter Sinnott-Armstrong has suggested something resembling the idea I have just put forward. He argued that individuals do not have a moral obligation to avoid taking one's car for leisure drives on Sundays to prevent global warming, because the impact on global warming of any individual driving is negligible; rather, as Sinnott-Armstrong argues, it is governments that should intervene to prevent global warming, if necessary by prohibiting individuals from recreational driving on Sundays. What individuals have a moral obligation to do is simply "to get governments to do their job" (Sinnott-Armstrong 2005, p. 312), that is, as I have said above, to actively support the appropriate policies. Presumably, SinnottArmstrong's argument could also be applied to the case of vaccination and herd immunity: individuals' duty to prevent negative collective outcomes includes the duty to support effective policies with the potential for preventing those outcomes. Contrary to Sinnott-Armstrong's thesis, I have provided here an argument, based on fairness, to the effect that individuals also have a moral obligation to contribute to the containment of global warming or to herd immunity by avoiding recreational driving on Sundays or by being vaccinated, respectively; they have these moral obligations even if their individual contribution to the collective cause is negligible. In any case, what matters for the purposes of the present discussion is that individuals fulfil their moral obligations to contribute to desirable collective outcomes (such as herd immunity) also by supporting policies that guarantee that herd immunity is realized.

Now, as we have seen, Sinnott-Armstrong says that individuals ought to "get governments to do their jobs". But what is governments" "job" with regard to vaccination policies? In other words, what are states' institutional responsibilities? Not everybody will agree with the following principle, and not everywhere is this principle equally accepted, but here I will assume that most people will agree with my understanding: a state has the moral responsibility to protect and promote individuals' health, especially that of the most vulnerable people (such as those who cannot be vaccinated), by at least controlling those factors that (1) affect individual health, (2) are not under an individual's control, and (3) that the state can permissibly control. For example, many countries have in recent decades implemented policies prohibiting smoking in public spaces in order to safeguard the health of non-smokers. If I am a non-smoker, other people's smoke in public spaces is a factor that would affect my health, that is not under my 
control, and that the state can permissibly control. However, in fulfilling its moral duty to protect vulnerable people's health, a state is not morally justified in doing just anything in its power; for example, to go back to infectious diseases, a state is normally not morally justified in quarantining individuals with measles or the flu in order to prevent other individuals from being infected. What, then, ought a state to do in order to protect vulnerable people from vaccine infectious diseases by remaining within its ethical boundaries? What are the limits of a state's moral obligation to protect the health of a community? Questions about what a state ought to do are inseparable from questions about what a state may permissibly do in order to fulfil its moral obligation. From what I have said so far, a state may permissibly fulfil its moral responsibility to protect individual and public health by requiring individuals to fulfil their individual moral obligations; for example, since vaccination is an individual moral obligation, as I have argued in this chapter, the state is justified in requesting individuals to be vaccinated in order to realize herd immunity, given that by doing so the state would not be requesting individuals to do anything supererogatory. Besides, state policies aimed at realizing herd immunity are further justified by the fact that individuals have a moral obligation to support such policies. Thus, the argument I have provided suggests that a state has a moral obligation to at least ensure that herd immunity is realized within its jurisdiction. Such institutional obligation results from the combination of a moral duty to protect vulnerable individuals' health and the ethical acceptability of vaccination policies that individuals have a moral obligation to support.

\section{CONCLUSION}

Before concluding and taking the next step, let me very briefly summarize the content of this chapter. I have argued that ( 1 ) individual rights to be protected from vaccine-preventable infectious diseases generate a collective obligation, which I have conceptualized as aggregative or shared responsibility, to realize herd immunity; (2) such collective obligation generates an individual obligation for every member of a community both to be vaccinated, unless there are medical reasons that would make vaccination supererogatory, and to support policies that allow to realize herd immunity; and (3) such individual obligations to support effective vaccination policies, together with the principle that states ought to protect individuals' health at least with regard to those factors that are under its 
control, generate the institutional responsibility to implement vaccination policies that can at the very least realize herd immunity.

Now, what specific types of policies individuals have a moral obligation to support, and institutions have the responsibility to implement, depends on the efficacy of possible alternative policies in realizing herd immunity and on their moral costs, for example, in terms of liberty infringements and fairness violations. Other things being equal (e.g., if two types of policies are equally effective in realizing herd immunity), less intrusive policies are to be preferred (Verweij ad Dawson 2004) according to a widely shared principle of "least restrictive alternative" in public health. The analysis and application of this principle to vaccination policies will be the topic of the next chapter. The reason why a principle of least restrictive alternative requires a separate discussion is that it raises more problems than it actually solves. In particular, one might ask ( 1 ) which vaccination policies can be considered less restrictive than others, and therefore ought to be preferred, and (2) what goal exactly ought to be pursued through vaccination policies, that is, whether herd immunity or something else. I will address these two questions in Chaps. 3 and 4, respectively. In Chap. 3, I will assume the widely shared view that herd immunity should be the goal of vaccination policies, which also follows from the arguments I have provided in this chapter; in Chap. 4, I will suggest that vaccination policies ought to be more ambitious: the fact that in this chapter I have argued that vaccination policies should at least aim at herd immunity does not mean that they should not aim at something even more ambitious, if some justification for this more ambitious target can be provided.

\section{REFERENCES}

Aas, S. (2015). Distributing Collective Obligation. Journal of Ethics and Social Philosophy, 9, 3.

Björnsson, G. (2014). Essentially Shared Obligations. Midwest Studies in Philosophy, 38(1), 103-120.

Bratman, M. E. (1993). Shared Intention. Ethics, 104(1), 97-113.

CDC (Centers for Disease Control and Prevention). 2018a. Measles, Mumps, and Rubella (MMR) Vaccine Safety. At https://www.cdc.gov/vaccinesafety/vaccines/mmr-vaccine.html. Accessed 28 Oct 2018.

CDC (Centers for Disease Control and Prevention). (2018b). Guillain Barré Syndrome. At https://www.cdc.gov/vaccinesafety/concerns/guillain-barresyndrome.html. Accessed 7 Aug 2018. 
Collins, S. (2013). Collectives' Duties and Collectivization Duties. Australasian Journal of Philosophy, 91(2), 231-248.

Dawson, A. (2007). Herd Protection as a Public Good: Vaccination and Our Obligations to Others. In A. Dawson \& M. Verweij (Eds.), Ethics, Prevention, and Public Health (pp. 160-178). Oxford: Clarendon Press.

Flanigan, J. (2014). A Defense of Compulsory Vaccination. HEC Forum: An Interdisciplinary Journal on Hospitals' Ethical and Legal Issues, 26(1), 5-25.

French, P. (1984). Collective and Corporate Responsibility. New York: Columbia University Press.

Giubilini, A., Douglas, T., \& Savulescu, J. (2018). The Moral Obligation to Be Vaccinated: Utilitarianism, Contractualism, and Collective Easy Rescue. Medicine, Health Care, and Philosophy. https://doi.org/10.1007/s11019018-9829-y.

Goodin, R. (1998). Social Welfare and Individual Responsibility: For and Against. Cambridge: Cambridge University Press.

Held, V. (1970). Can a Random Collection of Individuals Be Morally Responsible? Journal of Philosophy, 67(14), 471-481.

Isaacs, T. (2011). Moral Responsibility in Collective Contexts. New York: Oxford University Press.

Isaacs, T. (2014). Collective Responsibility and Collective Obligation. Midwest Studies in Philosophy, 38(1), 40-57.

List, C., \& Pettit, P. (2011). Group Agency. The Possibility, Design, and Status of Corporate Agents. Oxford: Oxford University Press.

Looker, C., \& Kelly, H. (2011). No-Fault Compensation Following Adverse Events Attributed To Vaccination: A Review of International Programmes. Bulletin of the World Health Organization, 89(5), 371-378.

May, L. (1990). Collective Inaction and Shared Responsibility. Nous, 24(2), 269-277.

May, L. (1998). Collective Inaction and Responsibility. In P. French (Ed.), Individual and Collective Responsibility. Rochester: Schenkman Books.

Mello, M. (2008). Rationalizing Vaccine Injury Compensation. Bioethics, 22(1), $32-42$.

Oxford Vaccine Group. (2016). Herd Immunity. University of Oxford. Retrieved January 18, 2017, from http://www.ovg.ox.ac.uk/herd-immunity

Parfit, D. (1984). Reasons and Persons. Oxford: Clarendon Press.

Pettit, P. (2007). Responsibility Incorporated. Ethics, 117, 171-177.

Pinkert, F. (2014). What We Together Can (Be Required to) Do. Midwest Studies of Philosophy, 23, 187-202.

Savulescu, J. (2007). Future People, Involuntary Medical Treatment in Pregnancy, and the Duty of Easy Rescue. Utilitas, 19(1), 1-20.

Scanlon, T. (1998). What We Owe to Each Other. Cambridge, MA: Harvard University Press. 
Schwenkenbecher, A. (2013). Joint Duties and Global Moral Obligations. Ratio, 26, 310-328.

Singer, P. (1972). Famine, Affluence, and Morality. Philosophy and Public Affairs, I(3), 229-243.

Sinnott-Armstrong, W. (2005). It Is Not My Fault: Global Warming and Individual Moral Obligations. In W. Sinnott-Armstrong \& R. Howarth (Eds.), Perspectives on Climate Change (pp. 221-253). Amsterdam: Elsevier.

Verweij, M. (2005). Obligatory Precautions Against Infections. Bioethics, 19(4), $323-335$.

Verweij, M., \& Dawson, A. (2004). Ethical Principles for Collective Immunization Programs. Vaccine, 22, 3122-3126.

WHO (World Health Organization). 2018. Influenza (Seasonal). At http://www. who.int/news-room/fact-sheets/detail/influenza-(seasonal). Accessed 28 Oct 2018.

Wringe, B. (2010). Global Obligations and the Agency Objection. Ratio, 23(2), 217-231.

Wringe, B. (2014). From Global Collective Obligations to Institutional Obligations. Midwest Studies in Philosophy, 38(1), 171-186.

Wringe, B. (2016). Collective Obligations: Their Existence, Their Explanatory Power, and Their Supervenience on the Obligations of Individuals. European Journal of Philosophy, 24(2), 472-497.

Open Access This chapter is licensed under the terms of the Creative Commons Attribution 4.0 International License (http://creativecommons.org/licenses/ by $/ 4.0 /$ ), which permits use, sharing, adaptation, distribution and reproduction in any medium or format, as long as you give appropriate credit to the original author(s) and the source, provide a link to the Creative Commons license and indicate if changes were made.

The images or other third party material in this chapter are included in the chapter's Creative Commons license, unless indicated otherwise in a credit line to the material. If material is not included in the chapter's Creative Commons license and your intended use is not permitted by statutory regulation or exceeds the permitted use, you will need to obtain permission directly from the copyright holder.

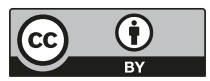

